\title{
La Jurisdicción de Marina en las antiguas Ordenanzas para el gobierno y regimiento de la villa de Lepe.
}

Forma la costa de la provincia de Huelva, o sea, desde la desembocadura del Guadiana a la del Guadalquivir, como todos sabemos, un arco de círculo en el que penetran las aguas del Atlántico, originándose un gran choco, según se diría en lengua ibera (cho-co, cho-ko, chocoa, echea, en vascuence; chozo o choza, que decimos en español para designar ciertas viviendas, palabras que significan hogar, refugio, rincón); estuarios del Tinto y del Odiel, colocados en lo más hondo, en lo más interno, o alejados de los extremos de aquel arco, en lo más profundo del "seno marítimo de Huelva" (hay quien cree que procede de aquí el llamar choqueros a los naturales de Huelva), refugio admirable ciertamente; aguas que bañan la parte de nuestra provincia que mira al mar, pletórica de recuerdos históricos.

Recostada sobre una colina rocosa, blanca y alegre, Ayamonte, capitalidad del Marquesado que crearon los Reyes Católicos, otorgándolo a don Pedro de Zúñiga y Guzmán; ciudad que se mira en el Guadiana, el antiguo Anas, y dejando la isla de la Canela..., navegamos hacia Levante..., almadrabas..., y en la costa, con fondo de pinares, allá entre esteros, Isla Cristina, donde los normandos, vencidos y arrojados del Guadalquivir, permanecieron algún tiempo haciendo frecuentes correrías por tierra.

Barra del Rompido, del Río Piedras, que trae a nuestra memoria la participación de los hombres de Cartaya y más propia- 
mente de Lepe, en los descubrimientos y exploraciones de la costa de América, desde Rodrigo Pérez de Acevedo, conocido por "Rodrigo de Triana"...; en "El Terrón", en el Río Piedras, hubo astilleros en que se construyeron, por orden del Rey Católico, las naves con que Solís, Vicente Yáñez Pinzón y el piloto de Lepe, Francisco de Torres, cuñado de Solís, zarparon de aquel río (8 de octubre de 1515) descubriendo el Río de la Plata.

Las costas bañadas por ese histórico mar de Huelva, desde el río Guadiana al Piedras, de las que acabamos de dar una rapidisima visión, nos presentan un especial interés, de tipo jurídico, que vamos a esbozar.

Conforme a los privilegios reales otorgados a los Condes de Niebla, los antiguos Guzmanes, luego, en una de sus ramas, entroncados con los Zúñigas y Sotomayor, Duques de Béjar, Marqueses de Gibraleón y también de Ayamonte..., esta Casa tenía, como señores de Ayamonte, de Lepe y de La Redondela, el pleno dominio de todas las tierras de sus Estados, que limitaban, al Sur con el mar Océano y al Este y Oeste, partiendo de la costa hacia el interior, respectivamente, con los rios Piedras y Guadiana.

Pleno dominio, el citado, que si bien comprendió durante no pocos años y sin dificultad alguna, de tipo jurídico, el dominio de las aguas de los ríos y las del propio mar (recordemos las polémicas de Grocio y de su refutador Selden, respectivamente, en sus obras "Mare liberum" y "Mare claussum», sobre soberanía del mar territorial, adquisic:ón y pérdida por prescripción, etc.), ya a fines del siglo xvirl empezó a producir perturbaciones.

Es interesante recordar, someramente, algunas disposiciones contenidas en las Ordenanzas de Lepe, dadas en 1484 a esta marinera Villa, por el primer Marqués de Ayamonte, don Pedro de Zúñiga, relativas a cosas de la mar, dispos:ciones que tienen su encuadramiento técnico jurídico, en el derecho público y aigunas de ellas en marítimo.

En la titulada "Ordenanza de la lota de esta Villa y del Terrón” (folio 23 bis al 26), entre otras, se contienen disposiciones referentes a que se pida permiso, por los navíos, antes de empezar la carga y descarga; a que todos los navíos que vend:eren fuera 
del lugar señalado, lo notifiquen en la Casa de la tabla de la Villa; a que todos los navíos tienen obligación de humar, en sus humeros o en otros, $y$ que todo el pescado del mar o del río se traiga a la lota.

Bajo el título "Mandamiento y ordenanzas de la ejecutoria y guarda de heredades y Panes" (folios $2 \hat{0}$ al 36 bis), se dispone lo conveniente a los fines que se expresan, encontrando un epígrafe curioso, cual es "Que nadie lleve uvas yendo a pescar, ni a navegar" (folio 27 bis), diciéndose, "así mistmo que ninguna persona que vaya a pescar ni a navegar lleve uvas al navío o barco doncle fuere a embarcar ni se les halle por el camino aunque sea de sus propias viñas, porque siendo que las llevan de las ajenas, hacen muchos daños. Que el que fuere así tomado pague de pena, si fuere de día seiscientos maravedises y el maestre del navío o barco pague la misma pena si consintiere llevar tales uvas en su barco y si lo encubriere..."

"Que no haya nasas", es el título de otra disposición (folio 45 bis), en la que se dice : "... por cuanto me fué hecha relación, que pocos años a esta parte en el río de mi Villa Lepe, de la barra adentro algunos vecinos de la dicha Villa, y de San Miguel y El Terrón hechan nasas para tomar xibias con piedras grandes para que las corrientes no las lleve y que las dichas piedras se quedan allí porque las cuerdas se rompen donde se llega $y_{1}$ retiene arena en gran cantidad que diz que hacen tener los navíos y barcos en gran daño de los hombres de la mar y sus tratos y pesquerías... Mando que de aquí adelante, en el dicho río de mi Villa de Lepe de la barra adentro, ningunas ni algunas personas vecinos de la dicha mi Villa de Lepe, ni San Miguel, ni El Terrón, ni otra parte no puedan hechar ni hechen las dichas nasas para pescar xibias, y si las quisieren pescar las pesquen como y según antes se solían hacer y $\sin$ que se causen los dichos daños, lo cual mando que guarden y cumplan, so pena de pagar cinco mil maravedises..." Precepto el que nos ocupa, totalmente comprendido en la competencia de las Autoridades de Marina, en nuestros días.

En otro de los títulos de las Ordenanzas que estudiamos, "Fructa por mar', se contienen las disposiciones, entre otras, siguientes : 
"... Mando que toda se lleve a la rramada (1) y no a otro puerto ni parte, con alvalá de todos tres fieles de la dicha tabla y q. sea de día y no de noche y que los fieles de la rramada... tengan libro... para que conciertê con los de la tabla y asentados los rronpan.. A Si mismo mando que ningún navío se Despache Sin la carta Cuenta delos fieles dela tabla delo q. se traiga para q. se corrija conel libro del tal navío porq. no concertando se e mienden e cobre los derechos q. penas degen lo de viere y estando bien se despache en buen ora...)

Otra Ordenanza "De los ostiones" (folios 86 bis-88), se da en La Redondela, el 18 de marzo de 1567, para Ayamonte, Lepe y La Redondela, a petición de las dos primeras, habiéndolas juntado el Marqués para tratar $1 . .$. del modo y horden que se a de tener en $A 1$ pescar de los ostiones en los rrios y esteros y mar de la costa deste marquesado...) Se pregonó en Lepe el jueves 20 del mismo citado marzo.

Se dice : "... que de pescarse... con rrastros en los dichos rrios y esteros bienen daño y perjuizio a mis vasallos y a las barras destos puertos y para lo rremediar y hazer lo que mas conbiene a la buena governacion destas dichas billas Mando que de a qui adelante No se puedan pescar los dhôs ostiones Con rrastros en los dichos esteros sino fuere a mano y que en la mar hôda, se pueden pescar, con los dhôs rrastros y como cada uno pudiere sopena que el que de otra manera pescare los dhôs ostiones... pague de pena dos mill mis... y mando que: Sean obligados los unos y los otros pescadores de los dhôs ostiones, a no los sacar fuera de la jurisçion a bender Sin dexar proveidas estas dhâs billas cada uno en su juridiçion delos que obieren menester para Su Mantenimi ${ }^{\circ}$ Como les será Mandado por los Justicias de cada un... so pena de por cada bes de seis cientos mirs...".

Antes hemos dicho, que ya a fines del siglo xvili, empezaron a producirse perturbaciones a causa del pleno dominio del Mar-

(1) La Enrramada, es un paraje próximo al río Piedras distante unos dos Kms. do Lepe; hoy no es posible que a él lleg'uen las embarcaciones. 
qués y aun por la simple posesión, de las tierras incluídas en lo que hoy constituye la zona marítimo-terrestre, siendo el Ayuntamiento de Lepe, en nombre del común de vecinos, quien constantemente reclamaba el libre uso de diversos parajes, tales como la dehesa de "El Piorno" y otros, y en lo que al presente estudio concierne, las marismas y la playa; perturbaciones las mentadas, relativas a playa y marismas, que tienen su origen jurídico, en la confus:ón constantemente sostenida en aquellos tiempos (y posteriormente, como lo reconoce la Real Orden de 23 de octubre de 1872), "entre lo que es playa o zona marítima deslindada, reconocida y legal, y lo que es la zona exacta y verdadera...n; confusión que se continúa aun después, ante la definición de lo que es playa, contenida en la Ley de aguas, de 3 de agosto de 1866, Ley que ya declara, son aquéllas (las playas), bienes de dominio nacional y de uso público.

Antes de 。esa declaración, fué tal el estado de violencia producido en los dominios del Marqués de Ayamonte, y el abuso en lo referente a la zona marítimo-terrestre y sus proximidades, que intervino el Tribunal de Justicia del Departamento de Marina de San Fernando, que en 9 de diciembre de 1830, dicta una sentencia, conforme a la doctrina y legislación vigentes, dejando bien sentado, dicho fallo, la competencia de las Autoridades de Marina. Esa competencia, que pone fin al estado de cosas existente, se recoge en la cláusula primera de la escritura de transacción, otorgada en Lepe, el 28 de julio de 1847, entre el Excmo. Sr. Marqués de Astorga y el Ayuntamiento de la Villa.

La cláusula citada, dice, textualmente: "1." La Villa de Lepe reconoce el dom:nio pleno del Excmo. Sr. Marqués de Astorga, en los terrenos, montes y arbolado de su término jurisdiccional, excluyendo únicamente, los que haya cedido, donado o enajenado con la competente autorización del actual poseedor o sus antecesores, en favor de la Villa o particulares con justos y legítimos títulos, conforme a la sentencia ejecutoria del Tribunal de Justicia del Departamento de Marina de San Fernando, fecha 9 de diciembre de 1830."

Queda, pues, acatado el fallo, por todos, y sentada la compe- 
tencia de la jurisdicción de Marina sobre la zona marítimo-terrestre que es objeto del presente estudio.

Con la desvinculación de los señorios y abolición de las prestaciones señoriales, en los años 1811 a 1837, con el acatamiento del fallo del Tribunal Departamental de San Fernando de 1830 y con el progresivo avance de la leg:slación, los derechos ejercitados por el Marquesado de Ayamonte, que hemos estudiado, pasaron al campo de la Historia.

\section{Luis Martínez y Sínchifz}

Correspondiente de la Real Aca.lemia de la Historia. Secretario de $1 .^{a}$ categoria, de Administración l.ocal. 